\title{
Occupation and authorship in The Indexer, 2000-09
}

\author{
Catherine Sassen
}

This study concerns the occupations of authors who contributed to volumes 22 through 27 of The Indexer. The occupational titles most often associated with the authors were indexer, librarian, writer, editor, library science faculty and researcher.

\section{Introduction}

'The diverse backgrounds of indexers contribute to the eclectic and interesting nature of our profession,' wrote Nancy Mulvany (1995: 241). She continued, 'Our backgrounds define much of our perspective about indexing.' The same statements could be made about authors who contribute to The Indexer, because their diverse backgrounds and perspectives contribute to the remarkable nature of the field of indexing, as well as to the journal itself.

The present study was conducted to explore the occupational backgrounds of recent contributors to The Indexer. Occupation is a factor considered in many authorship studies in the discipline of library and information sciences. Examples include studies by Olsgaard and Olsgaard (1980), Adamson and Zamora (1981), Schrader (1985), Buttlar (1991), Raptis (1992), Nisonger (1996), Lipetz (1999), and Fennewald (2007). Researchers such as Nisonger (1996: 398) and Buttlar (1991: 39) have justified authorship studies as a way of documenting the sociological characteristics of the literature of a discipline.

\section{Methodology}

Volumes 22 through 27 of The Indexer, published from 2000 through 2009, were examined in this study. Authorship information was gathered through personal examination of each issue. The byline accompanying each contribution was analyzed to identify each author. If the byline listed more than one author, information about each author was recorded.

'Authorship' was defined as the person or persons who were identified as the writers of articles, editorials, letters and reviews. Using the methodology of one of the earliest authorship studies in library and information science, each instance of authorship was considered as a separate case (Olsgaard and Olsgaard, 1980). Therefore, a contribution written through the collaboration of two authors was counted as two authorship cases. Multiple contributions written by the same author were counted separately. For example, if an author contributed one article in 2002 and another in 2005, each article was considered as a separate instance of authorship.

This study included articles, editorials, letters to the editor, and reviews. The category of 'articles' included historical and descriptive papers, quantitative research, position papers, conference presentations, case studies, biographies,
'Centrepieces,' bibliographies, and indexes. Contributions excluded from the study were brief news items, announcements of upcoming events, summaries of conferences, brief reports of awards, and reports on articles in earlier issues of The Indexer. Unsigned contributions were excluded, as well as contributions signed only by initials which were not readily identified. Also excluded were features compiled with the assistance of many contributors, such as 'Indexes Reviewed' and reports from national indexing societies.

Information about the authors' current and former occupations was gathered through several different sources. The researcher first collected information through an online survey administered in the fall of 2010. The researcher contacted as many authors as possible by email, and requested that they complete an online survey about their current and former occupations. Some email addresses for authors were found in their biographical information sketches in The Indexer. Other addresses were found in online directories accessed through the websites of national indexing societies. The editor of The Indexer provided some addresses.

Other sources were consulted to find occupational information about the remaining authors who were not covered by the survey responses. Biographies of indexers were consulted in From flock beds to professionalism: a history of index-makers (Bell, 2008). In addition, back issues of The Indexer were examined. The bylines and biographical information accompanying each relevant contribution in The Indexer were analyzed to identify the occupation of each author. If information about the occupation of the author was not found, additional issues of The Indexer were searched to determine if the author had published other contributions which included occupational information. Obituaries in The Indexer were consulted for deceased authors.

Of the 600 author cases covered by this study, occupational information was found for 571 (95 percent). The online survey provided information for 348 authors (58 percent). Issues of The Indexer supplied occupational information for 199 authors (33.17 percent). The biographies in From flock beds to professionalism (Bell, 2008) yielded occupational information for 24 authors in the study (4 percent). No occupational information was found for 29 authors (4.83 percent).

Each mention of an author's occupation was counted separately. Perhaps the most difficult aspect of this type of study is deciding how to group the occupations into meaningful categories. In this study, the category of 'writer' includes individuals who were identified as authors, writers, 
and technical writers. The category of 'editor' includes editors and editorial staff members. The category of 'library science faculty' includes both full-time and part-time faculty members affiliated with library schools. The category of 'teacher' includes authors identified as teachers or trainers who did not specify any affiliation with institutions of higher education. Of course, all faculty, teachers and trainers might have been grouped into an 'educator' category, but this would have obscured the significant number of contributions made by library science faculty members.

\section{Occupational distribution of all authors}

There were 1,727 instances of occupations associated with the 571 authors for whom information was found. The occupation mentioned most often was indexer (24.61 percent of all occupation cases), followed by librarian (12.22 percent), writer (9.79 percent), editor (8.28 percent), library science faculty (6.49 percent), and researcher (5.04 percent). The distribution of the occupations of all authors is summarized in Table 1 and Figure 1. When considering these numbers, it is important to remember that each mention of an author's occupation was counted separately. The average number of occupations associated with each author was 3.03.

Table I Occupations of all authors

\begin{tabular}{lcc}
\hline & Number & Percent \\
Indexer & 425 & 24.61 \\
Librarian & 211 & 12.22 \\
Writer & 169 & 9.79 \\
Editor & 143 & 8.28 \\
Faculty LS & 112 & 6.49 \\
Researcher & 87 & 5.04 \\
Other & 580 & 33.58 \\
Total & 1,727 & 100.00 \\
\hline
\end{tabular}

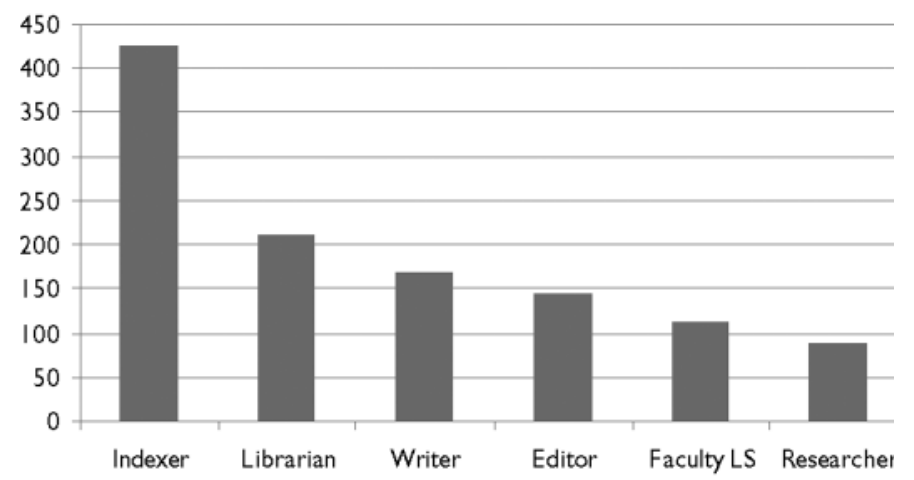

Figure I Occupations of all authors

\section{Articles}

Occupational information was found for 274 of the 288 authors of articles in this study. These authors were associated with 779 mentions of occupations. The occupation mentioned most frequently was indexer (20.54 percent), followed by librarian (12.97 percent), writer (9.5 percent),
Table 2 Occupations of authors of articles

\begin{tabular}{lcr}
\hline & Number & Percent \\
Indexer & 160 & 20.54 \\
Librarian & 101 & 12.97 \\
Writer & 74 & 9.50 \\
Editor & 69 & 8.86 \\
Faculty LS & 53 & 6.80 \\
Researcher & 47 & 6.03 \\
Other & 275 & 35.30 \\
Total & 779 & 100.00
\end{tabular}

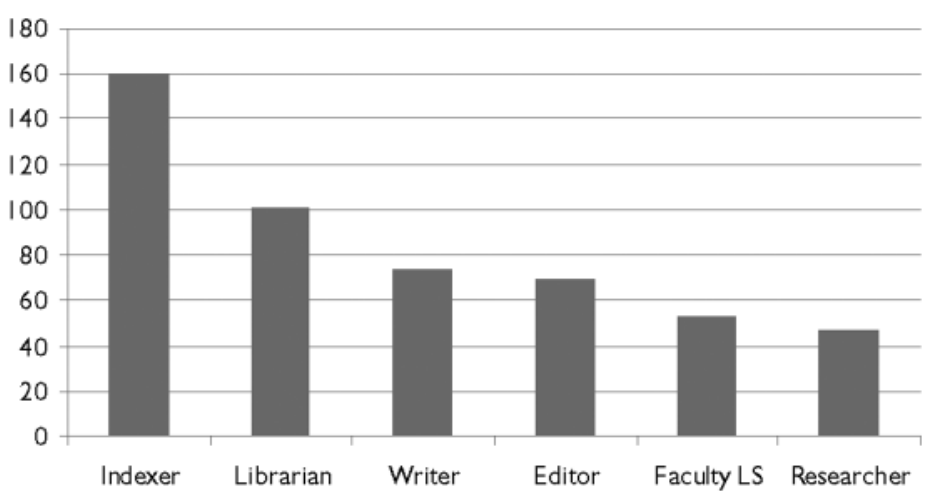

Figure 2 Occupations of authors of articles

editor (8.86 percent), library science faculty (6.8 percent), and researcher (6.03 percent). This distribution is illustrated in Table 2 and Figure 2.

\section{Editorials}

Thirty-eight author cases were associated with editorials in The Indexer during the period under review. Occupational information was found for 36 of these author cases. Many of these cases pertained to guest editors. Of the 98 mentions of occupations associated with the authors of editorials, 31.63 percent involved indexing. The occupations of diplomat and personnel selector were mentioned in 14.29 percent of all authorship cases, reflecting the background and contributions of the current editor of The Indexer, Maureen MacGlashan. The occupation of librarian was mentioned in 9.18 percent of all cases. The occupational distribution of authors of editorials is presented in Table 3 and Figure 3.

Table 3 Occupations of authors of editorials

\begin{tabular}{lcc}
\hline & Number & Percent \\
Indexer & 31 & 31.63 \\
Diplomat & 14 & 14.29 \\
Personnel selector & 14 & 14.29 \\
Librarian & 9 & 9.18 \\
Other & 30 & 30.61 \\
Total & 98 & 100.00
\end{tabular}




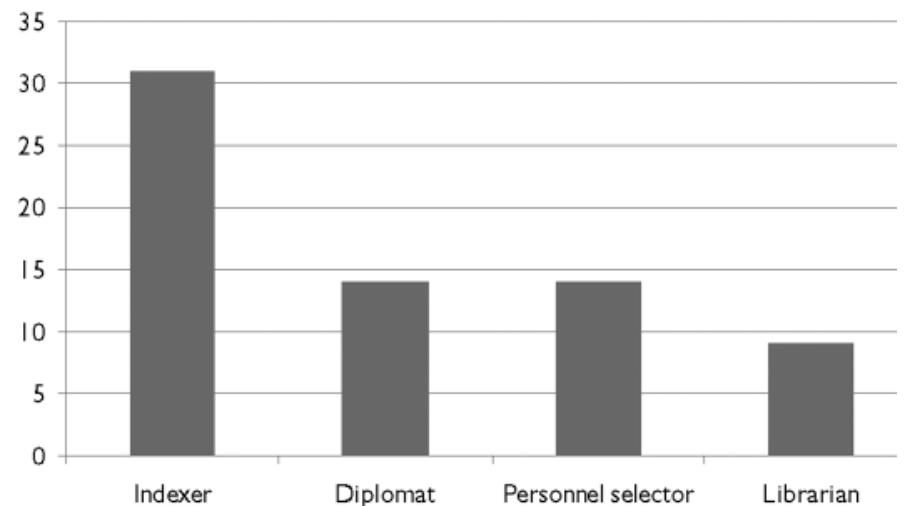

Figure 3 Occupations of authors of editorials

\section{Letters}

Thirty-two authors of letters were identified. Occupational information was found for 25 of these author cases. There were 101 mentions of occupations associated with the authors of letters. The occupation mentioned most often was indexer (18.81 percent), followed by librarian (10.89 percent), writer (8.91 percent), editor (7.92 percent), teacher (7.92 percent), and library science faculty (5.94 percent). The occupational distribution of authors of letters is summarized in Table 4 and Figure 4.

Table 4 Occupations of authors of letters

\begin{tabular}{lcc}
\hline & Number & Percent \\
Indexer & 19 & 18.81 \\
Librarian & 11 & 10.89 \\
Writer & 9 & 8.91 \\
Editor & 8 & 7.92 \\
Teacher & 8 & 7.92 \\
Faculty LS & 6 & 5.94 \\
Other & 40 & 39.60 \\
Total & 101 & 100.00 \\
\hline
\end{tabular}

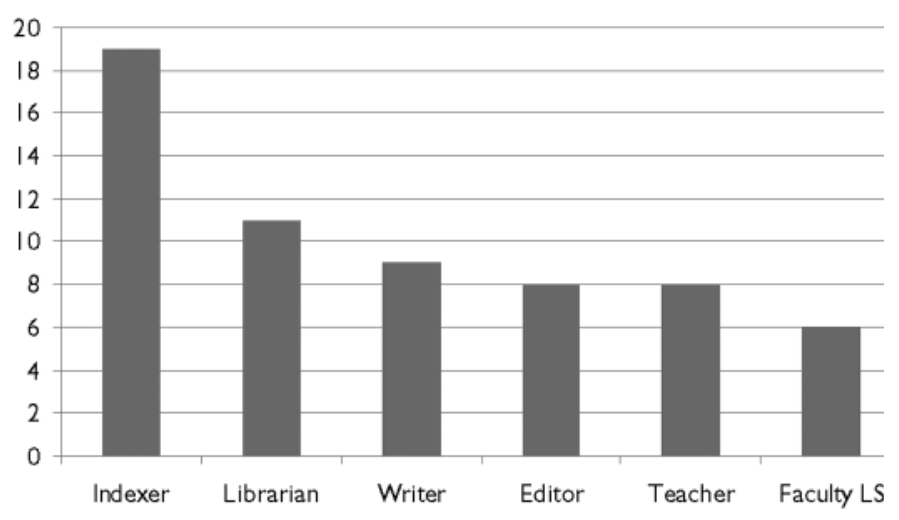

Figure 4 Occupations of authors of letters

Reviews

Occupational information was found for 236 of the 242 authors of reviews. Of the 749 mentions of occupations associated with these authors, 28.7 percent pertained to indexers. Other occupations were those of librarian (12.02
Table 5 Occupations of authors of reviews

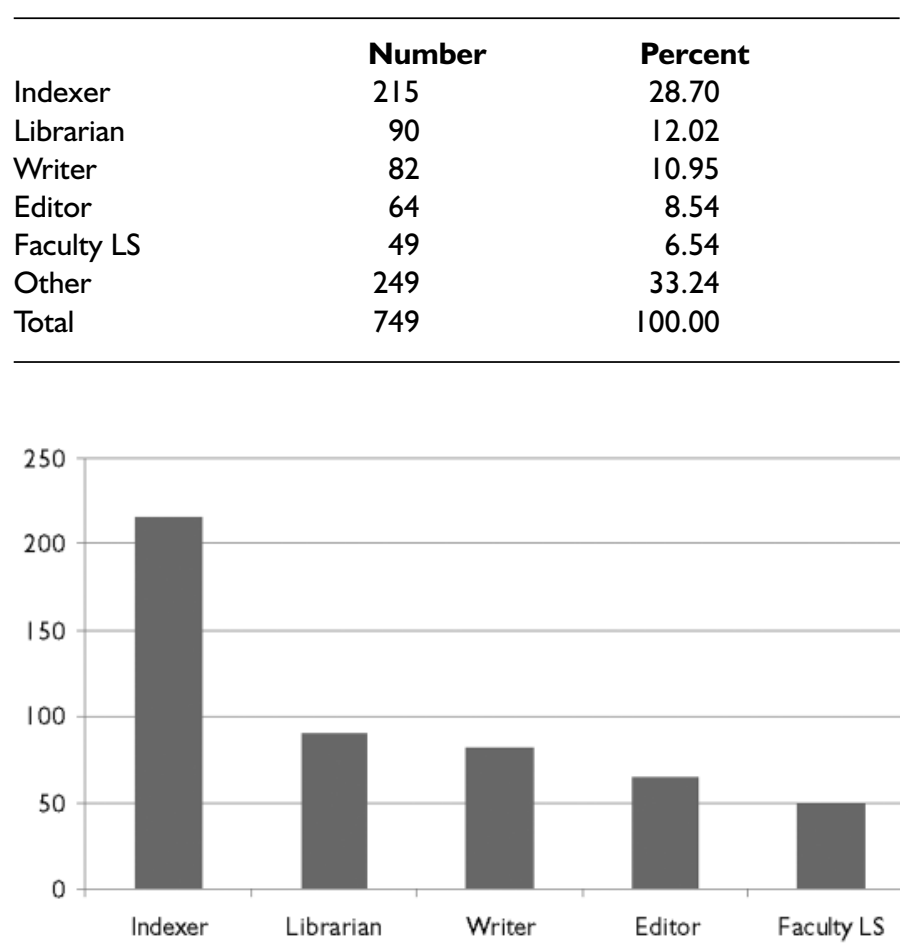

Figure 5 Occupations of authors of reviews

percent), writer (10.95 percent), editor (8.54 percent), and library science faculty (6.54 percent). The occupational distribution of authors of reviews is illustrated in Table 5 and Figure 5.

\section{Discussion}

Given the scope of The Indexer, it is not a surprise that the occupation of indexer is associated with the greatest number of authors in this study. The other occupational titles that were mentioned most often included librarian, writer, editor, library science faculty and researcher. All of these occupations are associated with indexing because of their relationship with the creation or the use of indexes.

Some of the diversity in this study reflects the careers of indexers who are associated with more than one occupation. 'It is a rare indexer working fulltime who does not also derive income from computer consultancy, editing, lecturing, library work, proofreading, software marketing, teaching or translation,' wrote Hazel K. Bell (2008: 17). Many indexers have had previous careers in related fields. For example, indexers who previously worked as writers, editors, or librarians have discussed their career paths in symposium articles entitled 'How I became an indexer' (Vickers et al, 1988) and 'Why I became an indexer' (Bancroft et al, 1969).

Librarians and library science faculty are associated with indexing because of its place in the curricula of library schools. Terris (1986) has written about the teaching of indexing in library schools in the United Kingdom. Weinberg and Dombek (1985) have documented indexing courses in library schools in the United States and Canada. Indexing continues to be taught in a number of schools of library and 
information science, as noted in the ASI 'Indexing courses and workshops' webpage (American Society for Indexing, 2011).

Librarians also are associated with indexing because much of their work involves information retrieval. Reference librarians use indexes as they search for information in response to questions from patrons. Some librarians create indexes to resources of particular interest to their patrons, such as local newspapers (Griffis, Cooper, and Headley, 2010).

There are historic ties between the Society of Indexers and library associations. Representatives from the Library Association and Aslib first joined the Society of Indexers' Council in 1958 (Knight, 1963: 87). The Chartered Institute of Library and Information Professionals (CILIP) is an 'Organization in Liaison' with the Society of Indexers (Society of Indexers, 2011).

What is the benefit of diversity among the authorship of The Indexer? The perspectives of authors from many different occupational backgrounds provide a dynamic forum for the exchange of ideas. According to the 'Notes for contributors' webpage of The Indexer (2011), 'articles are welcomed on all aspects of indexing and related matters and their application to the analysis, organization and accessibility of recorded knowledge and ideas.' It is only through a variety of perspectives that 'all aspects of indexing and related matters' may be thoroughly explored.

\section{References}

Adamson, M. C. and Zamora, G. J. (1981) 'Publishing in library science journals: a test of the Olsgaard profile.' College and Research Libraries 42(3), 235-41.

American Society for Indexing (2011) 'Indexing courses and workshops.' [online] www.asindexing.org/i4a/pages/index. cfm?pageid=3317 (accessed January 1, 2011).

Bancroft, R., Coole, R. D., Bedfordian, H. R., Bell, H. K., Binns, K., Wace M., and Dunn, F. T. (1969) 'Why I am an indexer.' Indexer 6(4), 165-73.

Bell, H. K. (2008) From flock beds to professionalism: a history of index-makers. New Castle, Delaware: Oak Knoll Press; Hatfield, Hertfordshire: HKB Press.

Buttlar, L. (1991) 'Analyzing the library periodical literature: content and authorship.' College and Research Libraries 52(1), $38-53$.

Fennewald, J. (2007) 'The ACRL conferences: a profile of its presenters.' College and Research Libraries 68(2), 107-18.

Griffis, D., Cooper, W., and Headley, S. (2010) 'Creating a local resources index/database.' The Serials Librarian 58(1-4), 215-18.

Indexer (2011) 'Notes for contributors.' [online] www. theindexer. org/index.php?option=com content\&task=view\&id=5\&Itemid $=6$ (accessed January 1, 2011).

Knight, G. N. (1963) 'Chairman's address.' Indexer 3(3), 87-9.

Lipetz, B. (1999) Aspects of JASIS authorship through five decades.' Journal of the American Society for Information Science 50(11), 994-1003.

Mulvany, N. (1995) 'Reflections on authorship and indexing.' Indexer 19(4), 241.

Nisonger, T. E. (1996) 'Authorship in library acquisitions: practice and theory.' Library Acquisitions: Practice and Theory 20(4), 395-419.
Olsgaard, J. N. and Olsgaard, J. K. (1980) 'Authorship in five library periodicals.' College and Research Libraries 41(1), 49-53.

Raptis, P. (1992) 'Authorship characteristics in five international library science journals.' Libri 42(1), 35-52.

Schrader, A. M. (1985) 'A bibliometric study of the JEL, 19601984.' Journal of Education for Library and Information Science 25(4), 279-99.

Society of Indexers (2011). Links [online] www.indexers.org.uk/ index.php?id=104 (accessed January 1, 2011).

Terris, O. (1986) 'Indexing in the curriculum of UK library schools.' Indexer 15(2), 89-90.

Vickers, J., Anderson, M. D., Humez, N. D., Gibson, J., Potparic, O., Jones, O. and Lavell, C. (1988) 'How I became an indexer.' Indexer 16(2), 117-22.

Weinberg, B. H. and Dombek, L. (1985) Education and training in indexing and abstracting: a directory of courses and workshops offered in the United States and Canada, with a bibliography of text-books used in indexing and abstracting courses, 3rd edn. New York: American Society of Indexers.

Catherine Sassen is principal catalog librarian at the University of North Texas. Email: Catherine.Sassendunt.edu

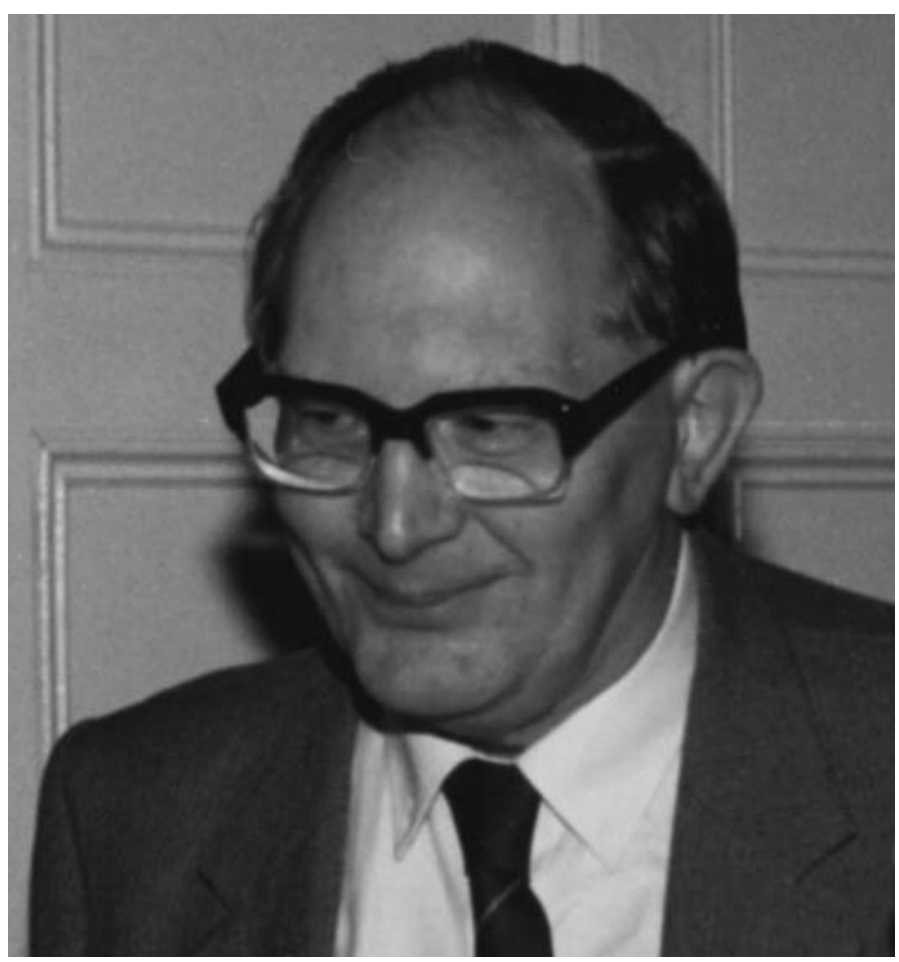

Ken Bakewell (see obituary opposite) at the SI conference in 1989. 
Copyright of Indexer is the property of Society of Indexers and its content may not be copied or emailed to multiple sites or posted to a listserv without the copyright holder's express written permission. However, users may print, download, or email articles for individual use. 